Article

\title{
Actions Speak Louder than Words: Investigating the Interplay between Descriptive and Injunctive Norms to Promote Alternative Fuel Vehicles
}

\author{
Muhammad A. Saleem ${ }^{1, *,+} \mathbb{D}$, Hina Ismail ${ }^{2,+}$ and Rao Akmal Ali ${ }^{2,+}$ \\ 1 Asia Pacific College of Business and Law, Charles Darwin University, Ellengowan Dr, \\ Casuarina, NT 0810, Australia \\ 2 Department of Management, Faculty of Management Sciences, National University of Modern Languages, \\ Islamabad 4000, Pakistan; hina.ismail@numl.edu.pk (H.I.); rakali@numl.edu.pk (R.A.A.) \\ * Correspondence: muhammad.saleem@cdu.edu.au; Tel.: +61-08-8946-8814 \\ + All authors contributed equally to this article.
}

check for updates

Citation: Saleem, M.A.; Ismail, H.; Ali, R.A. Actions Speak Louder than Words: Investigating the Interplay between Descriptive and Injunctive Norms to Promote Alternative Fuel Vehicles. Sustainability 2021, 13, 9662. https://doi.org/10.3390/su13179662

Academic Editor: Ans Vercammen

Received: 12 July 2021

Accepted: 23 August 2021

Published: 27 August 2021

Publisher's Note: MDPI stays neutral with regard to jurisdictional claims in published maps and institutional affiliations.

Copyright: (c) 2021 by the authors. Licensee MDPI, Basel, Switzerland. This article is an open access article distributed under the terms and conditions of the Creative Commons Attribution (CC BY) license (https:/ / creativecommons.org/licenses/by/ $4.0 /)$.

\begin{abstract}
Environmental problems are escalating. Alternate fuel vehicles are a technologically viable solution to curb transport-related pollution and greenhouse gas emissions that cause environmental problems. Based on the theory of norms-driven behavior, this study explains how the underlying facets of subjective social norms (injunctive and descriptive) are linked with personal norms (integrated and introjected) and how this linkage leads to eco-socially conscious consumer behavior related to the choice and use of personal cars. Data were collected from 687 automobile customers from eight large cities in Pakistan. The partial least squares structural equation modeling approach was employed to test the hypothesized relationships of the study. The results showed that subjective norms are positively associated with personal norms, and both together lead to eco-socially conscious consumers' behavior related to the choice and use of personal cars. Implications for marketers are suggested to promote alternate fuel vehicles and the eco-social use of personal cars.
\end{abstract}

Keywords: integrated norms; introjected norms; eco-social use; eco-social purchase; descriptive norms; injunctive norms

\section{Introduction}

The internationally recognized problems related to climate change, global warming, and greenhouse gas emissions (GhGs) are linked to economic growth and escalated consumption patterns [1,2]. Economic activities and changes in consumption patterns are fueled by several industries, of which the personal transport sector is the most important as it provides access to health, education, and jobs [3,4]. Consequently, the personal transportation sector produces the highest percentage of emissions of GhGs, which causes an ominous deterioration of the natural environment. The $\mathrm{CO}_{2}$ (a major GhG) emissions from personal cars constitute $45 \%$ of the total emissions generated by the overall transport sector [5], indicating the importance of the personal cars segment in reducing carbon footprints. The $\mathrm{CO}_{2}$ emissions from personal cars are a consequence of petrol and diesel fuel based automobile technology and, at times, excessive use of personal cars by the consumers [6,7].

The significant technological leaps of the automobile industry in developing environmentfriendly cars (hereafter called alternative fuel vehicles (AFVs)) have made it possible to reduce personal cars' emission levels. Additionally, using transportation means other than personal cars (public transport, cycle, or carpooling) may reduce $\mathrm{CO}_{2}$ emissions [5]. Therefore, it is essential to institute a research-informed policy guiding interventions to promote AFVs and environment-oriented personal cars. However, consumers' behavior pertinent to the choice of AFVs and their use is driven by a set of intricate processes governed by several internal and external factors, including personal values, influence of others, available options, and brand reputation [8-10]. 
The current literature offers several models and frameworks for diffusion and adoption of AFVs, predominantly in the developed countries' context [11-15]. Some of these models ponder upon the influence of social and personal norms on customers' decision making process involving purchase of AFVs [16,17], however, there is little known about the objective patterns and wide-spread regularities manifested in norms-driven behavior influencing choice of AFVs. Additionally, in developing countries, there is a dearth of research explaining the motivations behind consumers' potential economic trade-offs for environmental well-being in choosing and using personal cars. Therefore, this current study aims at investigating the role of social and personal norms in predicting consumers choice and use of AFVs. In so doing, this study provides important guidelines for the marketers of AFVs, and policy makers, in designing effective strategy to promote AFV brand options.

\section{Background and Research Framework}

The fundamental postulates of normative conduct theory [18] and social identity theory [19] provide the basis for explaining the role of social norms in various types of human behaviors, particularly those related to the environment. While norms generally refer to socially sanctioned behaviors and are commonly approved in society (social norms), there appears to be a difference between types of norms based on how they are formed. Descriptive norms refer to one's perception of what others do (actual engagement of others in a particular behavior), while injunctive norms refer to one's perception of what others expect one to do (what others believe is right for one to do) [20]. Conceptually, the formation of descriptive norms about a particular behavior is influenced by the belief that others are also engaged in such behavior (hence called "is"). In contrast, injunctive norms are formed based on the belief that others expect or approve one's engagement in a particular behavior (hence the norms of "ought") [18]. As descriptive and injunctive norms are subjective perceptions of individuals that important others are engaged in specific behaviors (descriptive norms), or they (important others) expect individuals to engage in such behaviors (injunctive norms), they have been termed subjective norms in the theory of planned behavior (TPB) [21].

The classic theory of internalization is the other proposal that propagates behaviours influenced by transmission of norms [22]. However, the postulates of internalization theory argue that individuals' values related to pro-environmental behaviours are introjected through and primed by authority figures. Additionally, when strong social cues are missing, individual behaviour related to environment and altruism is primarily guided by induced moral reflection of individuals [20]. These assertions confirm Schwartz's [23] proposal that personal norms are critical drivers of behaviour in the absence of societal expectations or pressure.

Besides a consensus that both personal and social norms lead to pro-environmental behaviours, evidence on the impact of individual dimensions of the two normative pressures to predict any particular type of pro-environmental behaviour remains somehow convoluted.

\subsection{Subjective Norms: Descriptive and Injunctive Norms}

The classification of descriptive and injunctive norms comes from normative conduct theory [24] and social identity theory [19]. Descriptive norms provide a useful decisionmaking reference to individuals in choosing which action/behavior is appropriate in a particular situation [25]. This is why descriptive norms positively influence very complex behaviors, particularly those encompassing environmental choices. For instance, Kim and Lee [26] reported that customers of apparel brands showed a positive inclination toward purchasing brands that donated a certain amount of their revenues for environmental protection when they found that other shoppers were doing the same.

Injunctive norms are driven by the belief that engaging in (or refraining from) a particular behavior is acceptable to (or expected by) important others [20]. The TPB posits that social pressure stimulates individuals' conformity to expected behavior based on 
all or any of the powers, including reward, coercion, legitimacy, experience, or referent strength [21]. Thus, it can be implied that people commit to a socially desired behavior influenced by their social groups with the help of pressure exerted by the powers mentioned above [18]. The relationship between descriptive and injunctive norms with targeted behavior(s) has been conceptually debated based on internalization, social identity, and rational choice theories by Morris and Hong [20], who describe perceived injunctive and descriptive norms as direct predictors of targeted behavior as well as through the mediating role of personal norms. A plethora of research is available to provide evidence regarding the impact of injunctive norms in shaping any volitional behavior or behavioral intentions. For instance, Jiang and Ling [27] noted that fatigued drivers ceased to drive when influenced by accompanying family or friends' advice. In a systematic review of the literature, Farrow and Grolleau [28] reported that injunctive and descriptive norms hold distinctive importance in predicting various pro-environmental behaviors. Similar findings were reported from other recent reviews by Melvin and Elliott [29] and Bergquist and Nilsson [30].

Additionally, several studies have been conducted to explain the impact of descriptive and injunctive norms on transport choice and use behaviors. Doran and Larsen [31] conducted a study on the behavior of tourists visiting New Zealand and found that tourists were willing to pay more for environmentally friendly means of transportation when they believed that people important to them were doing so and had the same expectations of them (tourists). Similar findings were reported in studies conducted to explain the adoption of plug-in hybrid vehicles [4], adoption of AFVs and curtailment behaviors [32], and loyalty to public bike systems [5].

Based on the above lines of arguments, this study posits that,

Hypothesis $\mathbf{1}(\mathbf{H 1} \mathbf{a}, \mathbf{b})$. Descriptive norms are positively associated with the eco-social purchase (H1a) and eco-social use (H1b) of personal cars.

Hypothesis $\mathbf{2}(\mathbf{H} 2 \mathbf{a}, \mathbf{b})$. Injunctive norms are positively associated with the eco-social purchase (H2a) and eco-social use (H2b) of personal cars.

\subsection{Personal Norms: Introjected and Integrated Norms}

The classis theory of internalization provides basis for categorizing personal norms into introjected and integrated components [20]. Personal norms relate to the sense of self-concept and a felt moral obligation to behave in a particular manner [23]. Social norms are others-induced pressure to comply with socially acceptable behaviors, while personal norms are self-induced standards driven by internalized values of morality (integrated norms) and pride or guilt (introjected norms) [18]. Introjected personal norms are motivated by guilt avoidance or expression of pride, whereas integrated personal norms are manifested in moral evaluation using self-reasoning and empathy [22]. The norm activation model ascribes personal norms as core elements of altruistic and environmentfriendly behaviors or behavioral intentions [33]. While there is a debate on whether integrated norms or introjected norms are stronger in predicting specific behaviors, a common argument is that, as part of personal norms, both are positively associated with pro-environmental behaviors [34,35].

As personal norms are linked with individuals' internalized values, they may be expected to directly invoke behaviors consistent with self-interest or a specific altruistic cause (including pro-environmental behaviors). Literature supports the notion that there is a direct link between personal norms and various pro-environmental behaviors. For instance, Doran and Larsen [31] reported that domestic and international tourists visiting New Zealand showed a more significant interest in protecting the environment by choosing eco-friendly travel options under the influence of felt moral obligation (personal norms). A similar finding was previously reported by Klöckner and Ohms [36], who found personal norms to be instrumental in predicting organic milk choice in German supermarkets. Likewise, behaviors such as choice of public 
transport instead of a personal car [37], sustainable travel mode choice in urban areas [38], and eco-driving [34] have also been reported to be directly influenced by personal norms. Therefore, this study proposes the following:

Hypothesis $\mathbf{3} \mathbf{( H 3 a , b ) . ~ I n t e g r a t e d ~ n o r m s ~ a r e ~ p o s i t i v e l y ~ a s s o c i a t e d ~ w i t h ~ t h e ~ e c o - s o c i a l ~ p u r c h a s e ~}$ (H3a) and eco-social use (H3b) of personal cars.

Hypothesis $4 \mathbf{( H 4 a , b ) . ~ I n t r o j e c t e d ~ n o r m s ~ a r e ~ p o s i t i v e l y ~ a s s o c i a t e d ~ w i t h ~ t h e ~ e c o - s o c i a l ~ p u r c h a s e ~}$ (H4a) and eco-social use (H4b) of personal cars.

The interplay between social and personal norms has been elucidated by several studies in the stream of norms-driven behavior research. The work of Thøgersen [22] provides empirical evidence of the association of injunctive and descriptive norms with introjected and integrated norms for a range of environmentally responsible behaviors, including the purchase of organic milk, energy-saving light bulbs, source separating compostable kitchen waste, and the choice of public transport for work and shopping. While the extant research distinguishes between social and personal norms, many propound that important group members' expectations effectively introject self-regulation [39]. For instance, the psychoanalytical explanation of personality argues that the balance between superego and ego is attained through the introjection of 'the standards of parents, teachers, and other authority figures' [20]. However, if others' expectations (injunctive norms) fail to evoke introjected norms entirely, internal motivation (integrated norms), such as guilt avoidance, enforces adherence to expected behavior [40].

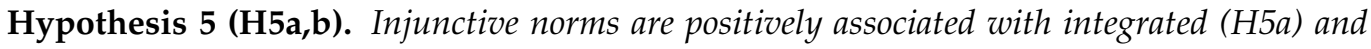
introjected norms (H5b).

Hypothesis $6 \mathbf{( H 6 a , b ) . ~ D e s c r i p t i v e ~ n o r m s ~ a r e ~ p o s i t i v e l y ~ a s s o c i a t e d ~ w i t h ~ i n t e g r a t e d ~ ( H 6 a ) ~ a n d ~}$ introjected norms (H6b).

\subsection{Mediating Role of Personal Norms}

The classic theory of internalization provides a detailed explanation of social normspersonal norms-pro-environmental behaviors associations. According to the internalization theory, the direct association of subjective social norms with pro-environmental behaviors may be regarded as oversimplified. From the perspective of cognitive processes, social expectations and sanctions generally affect individuals' definition of self and meanings of morality, and in so doing, remove inconsistencies in the way of reasoning and measuring empathy between individuals and society [20]. Consequently, an agreement is reached between individuals and society regarding acceptable behaviors, leading the individual to perform the behavior or develop behavioral intentions. While a direct association between social norms and pro-environmental behaviors may not be entirely disregarded, it is plausible to suggest that the link between social norms and pro-environmental behaviors is more conveniently established through personal norms.

The prediction of eco-social behaviors (such as environmentally friendly apparel product purchase, recycling, conservation, and organic food purchases) by personal norms, through the process of social norms' (injunctive and descriptive) internalization into personal norms (introjected and integrated), is well argued in the literature [41-43]. Savani and Wadhwa [44] found that Indian consumers were likely to change their clothing and travel choices under the influence of introjected norms induced through their authority figure (parents and teachers). Therefore, it can be proposed that the manipulation of injunctive norms can be instrumental in altering integrated and introjected norms and, consequently, elicitation of behavior desired by authority figures. The assertions described above are empirically tested in a recent study, where Doran and Larsen [31] found that injunctive and descriptive norms explain tourists' eco-friendly choice of travel options through the 
channel of integrated and introjected regulations. Similarly, Wenzig and Gruchmann [45] reported that injunctive and descriptive norms lead to integrated and introjected norms, thus ultimately predicting consumers' preference for local food.

The arguments mentioned above have been supported by the findings of several studies in the domain of pro-environmental behaviors. For instance, Bamberg and Hunecke [37], in their study, reported that German passengers' felt-guilt for using personal cars was enhanced when they perceived that people expect them to use public transport instead of personal cars, and this led to their public transportation choice behaviors. These findings reinforce that social pressure (both explicit and implicit) causes individuals' self-evaluation of their actions and may lead to engaging in pro-environmental behaviors. Based on the evidence reported above, this study proposes that:

Hypothesis $\mathbf{7}(\mathbf{H 7} \mathbf{a}, \mathbf{b})$. Integrated norms mediate the relationship between injunctive norms and eco-social purchase (H7a) and eco-social use (H7b) of personal cars.

Hypothesis $\mathbf{8}(\mathbf{H 8 a}, \mathbf{b})$. Introjected norms mediate the relationship between injunctive norms and eco-social purchase (H8a) and eco-social use (H8b) of personal cars.

Hypothesis $\mathbf{9}(\mathbf{H} \mathbf{9} \mathbf{a}, \mathbf{b})$. Integrated norms mediate the relationship between descriptive norms and eco-social purchase (H9a) and eco-social use (H9b) of personal cars.

Hypothesis $10(\mathbf{H 1 0 a}, \mathbf{b})$. Introjected norms mediate the relationship of descriptive norms with eco-social purchase (H1Oa) and eco-social use (H10b) of personal cars.

Based on the literature cited above, the model conceptualized in this study is presented in Figure 1.

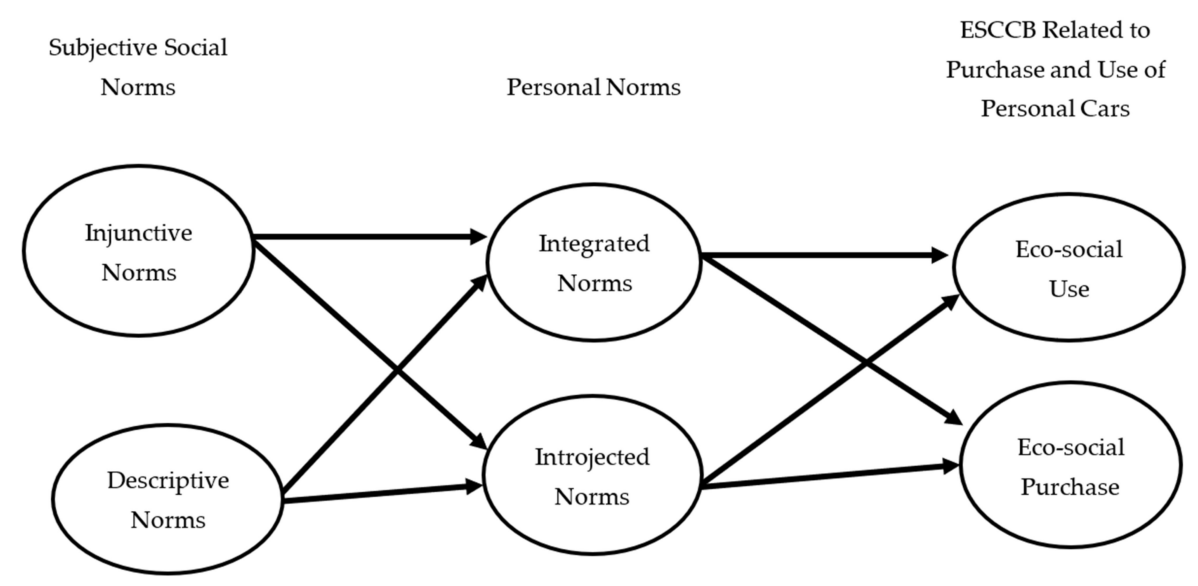

Figure 1. Proposed framework. Notes: ESCCB: eco-socially conscious consumer behavior.

\section{Materials and Methods}

\subsection{Participants and Procedure}

Recruitment of respondents followed a proportionate stratified random sampling procedure, based on the individual sales share of the three biggest automobile brands currently operating in Pakistan, that is, Honda, Toyota, and Suzuki motors, holding almost $89 \%$ of the total market share [46]. The choice of proportionate stratified random sampling was considered appropriate because the three automobile brands considered in this study constitute unique consumer segments whose representation is critical to the generalization of this study's results. In addition, this sampling method has been reported to provide greater statistical precision in the results [47]. The dealerships of the automobile brands mentioned above were selected randomly, proportionate to their sales share, and respondents were personally met by survey assistants at these dealerships 
to collect data through a structured questionnaire. Prior to actual data collection, all necessary approvals were obtained. The ethics approval for this study was granted under the approval number H6869 by the Human Research Ethics Committee (HREC) of James Cook University, Australia.

\subsection{Sample Size}

For sample size calculations, this study followed the guidelines provided by Kline [48], who recommended obtaining 20 observations for each free parameter to be estimated to make an adequate sample size in structural equation modeling (SEM). Considering the initial number of free parameters to be estimated (32) based on adopted scales, a sample size of $640(32 \times 20=640)$ was considered appropriate. Therefore, 1200 respondents were randomly recruited and contacted for data collection, anticipating 30-40 percent nonresponse, which is likely in survey methods using probability sampling techniques [49]. Finally, a total of $686(57.16 \%)$ usable responses were obtained, constituting a satisfactory response rate [50], meeting the sample size requirement of this study. Table 1 summarizes the details of the respondents.

Table 1. Demographic statistics of respondents.

\begin{tabular}{|c|c|c|c|}
\hline \multirow{2}{*}{ Variable } & \multirow{2}{*}{ Category } & \multicolumn{2}{|c|}{ Distribution } \\
\hline & & Frequency & Percentage \\
\hline \multirow{7}{*}{ Age } & $19-26$ & 436 & 63.6 \\
\hline & $>26-33$ & 128 & 18.7 \\
\hline & $>33-40$ & 78 & 11.4 \\
\hline & $>40-47$ & 6 & 0.9 \\
\hline & $>47-54$ & 22 & 3.2 \\
\hline & $>54-61$ & 12 & 1.7 \\
\hline & $>61$ & 4 & 0.6 \\
\hline \multirow{2}{*}{ Gender } & Male & 382 & 55.7 \\
\hline & Female & 304 & 44.3 \\
\hline \multirow{10}{*}{ Education } & No formal education & 6 & 0.9 \\
\hline & Primary (year 5) & 3 & 0.4 \\
\hline & Secondary school certificate (year 10) & 2 & 0.2 \\
\hline & Higher secondary school certificate (year 12) & 33 & 4.8 \\
\hline & Undergraduate (Year 16) & 172 & 25.1 \\
\hline & Masters (year 18) & 230 & 33.5 \\
\hline & MBBS or BDS & 186 & 27.1 \\
\hline & DVM & 18 & 2.6 \\
\hline & $\mathrm{BE}$ & 3 & 0.4 \\
\hline & Others & 33 & 4.8 \\
\hline \multirow{7}{*}{ Income $^{a}$} & $45,000-55,000$ & 269 & 39.2 \\
\hline & $>55,000-65,000$ & 65 & 9.5 \\
\hline & $>65,000-75,000$ & 116 & 16.9 \\
\hline & $>75,000-85,000$ & 47 & 6.9 \\
\hline & $>85,000-95,000$ & 57 & 8.3 \\
\hline & $>95,000-105,000$ & 50 & 7.3 \\
\hline & $>105,000$ & 82 & 12.0 \\
\hline \multirow{3}{*}{ Location } & City & 594 & 86.6 \\
\hline & Suburb & 27 & 3.9 \\
\hline & Village & 65 & 9.5 \\
\hline \multirow{4}{*}{ Marital status } & Single & 483 & 70.4 \\
\hline & Married & 186 & 27.1 \\
\hline & Divorced & 14 & 2.0 \\
\hline & Widowed & 3 & 0.4 \\
\hline
\end{tabular}

Notes: ${ }^{\text {a }}$ : Income is given in Pak Rupee (exchange rate: USD 1 = 125 PKR), income divisions start from PKR 45,000 onwards because this is the lower limit for financing options from financial institutions in Pakistan. MBBS: Bachelor of Medicine, Bachelor of Surgery, BDS: Bachelor of Dental Surgery, DVM: Doctor of Veterinary Medicine, BE: Bachelor of Engineering. 
Primary data analysis, including descriptive and exploratory factor analysis (EFA), was conducted using program SPSS v. 25.0 (IBM SPSS, Armonk, NY, USA).

\subsection{Measurement Instrument}

As noted earlier, subjective norms are determined by (i) the expectations (normative pressure) of important others regarding performing or not performing a specific behaviorinjunctive norms, and (ii) perceptions that others are (or are not) involved in performing a particular behavior-descriptive norms [18]. Injunctive norms were measured with two components, as suggested by Fishbein and Ajzen [51]: normative beliefs (measured by six items, $\alpha=0.785$ ) and motivations to comply (measured by four items, $\alpha=0.745)$. Similarly, adapted from existing studies [52], descriptive norms were measured using four items $(\alpha=0.779)$. In line with existing studies of a similar kind [16,17], this study utilized sevenitem scales to measure integrated and introjected norms separately ( $\alpha$ integrated $=0.830$; $\alpha$ introjected $=0.796$ ). ESCCB related to and use of personal cars refers to a specific set of behaviors including elements of social and ecological motivations in using personal cars intending to reduce the impact of personal cars on the environment [7]. In this study, we measured intentions rather than actual behavior. The reason behind measuring intentions include: (1) intentions are closest proxy of actual behavior [21], (2) self-report behaviors are treated almost similarly as intentions in the literature [21], and (3) measurement of actual behavior is somehow complicated and may require more time in data collection [17]. The construct was measured with a nine-item scale comprising interrelated factors (eco-social use, eco-social purchase). Each factor was measured using three items adapted from an existing study $[6,53]$. The eco-social use dimension measured respondents' propensity to ethically use personal cars, while the eco-social purchase dimension measured respondents' predisposition toward purchasing AFVs. The data showed that the ESCCB scale converged in two dimensions (eco-social use: five items, $\alpha=0.839$, and eco-social purchase: three items, $\alpha=0.837)$. Responses on all items were captured using seven-point Likert-based scale $(1=$ 'strongly disagree', $7=$ 'strongly agree' $)$. The description of the measurement instrument is provided in Appendix B, Table A2. The actual survey instrument included other items as well pertaining to the larger project of which this study is one part.

\section{Results}

\subsection{Respondents' Profile}

The respondents' demographic profile is provided in Table 1. Of the total respondents, $55.7 \%$ were male, and $44.3 \%$ were female. The female ratio in the sample is almost at par with the male representation, reflecting growing female participation in critical decision making in Pakistan's society [54]. Slightly more than $63 \%$ of the respondents were in the age bracket of 19-26 years, compared with the national population figures (i.e., $56 \%$ in the age backet of 15-29) [55].

\subsection{Measurement Model Validation}

As the data were collected using a single source (survey instrument) and technique (personal contact), there was potential for common method variance (CMV), resulting in a common method bias (CMB) [56]. This study applied Harman's single-factor test to detect CMV using EFA. All survey items were used to run the test, and the results showed that no single factor alone explained variance of greater than $25 \%$, confirming that CMB is not a critical issue for this study [57]. The results of the EFA are reported in Table 2. The study further verified the non-existence of CMB following the proposal of Kock [58], who noted that "variance inflation factor (VIF) values greater than 3.3 indicate pathological collinearity and typical method bias". A factor-level assessment of VIFs for all constructs was conducted to verify this condition, which showed that VIFs for all constructs were below the threshold value of 3.3 (see Table 3). Therefore, the model can be considered free of the CMB. 
Table 2. EFA, composite reliability, and AVEs.

\begin{tabular}{|c|c|c|c|c|c|c|}
\hline Constructs & Dimension & Items & Standardized Loadings & AVE & $\alpha$ & CR \\
\hline \multirow{12}{*}{$\begin{array}{l}\text { Subjective Social } \\
\text { Norms }\end{array}$} & \multirow{4}{*}{$\begin{array}{l}\text { Injunctive } \\
\text { Norms-Belief } \\
\text { Strength }\end{array}$} & & & 0.700 & 0.785 & 0.875 \\
\hline & & SN1 & 0.834 & - & - & - \\
\hline & & SN2 & 0.869 & - & - & - \\
\hline & & SN3 & 0.806 & - & - & - \\
\hline & \multirow{4}{*}{$\begin{array}{c}\text { Injunctive } \\
\text { Norms-Motivation to } \\
\text { Comply }\end{array}$} & & & 0.661 & 0.745 & 0.854 \\
\hline & & MotCply1 & 0.795 & - & - & - \\
\hline & & MotCmply2 & 0.832 & - & - & - \\
\hline & & Motcmply3 & 0.811 & - & - & - \\
\hline & \multirow{4}{*}{ Descriptive Norms } & & & 0.692 & 0.779 & 0.871 \\
\hline & & DescNorm1 & 0.801 & - & - & - \\
\hline & & DescNorm2 & 0.825 & - & - & - \\
\hline & & DescNorm3 & 0.869 & - & - & - \\
\hline \multirow{11}{*}{ Personal Norms } & \multirow{5}{*}{ Introjected Norms } & & & 0.618 & 0.796 & 0.866 \\
\hline & & PersIntroNorm3 & 0.801 & - & - & - \\
\hline & & PersIntroNorm4 & 0.859 & - & - & - \\
\hline & & PersIntroNorm5 & 0.766 & - & - & - \\
\hline & & PersIntroNorm6 & 0.712 & - & - & - \\
\hline & \multirow{6}{*}{ Integrated Norms } & & & 0.596 & 0.830 & 0.880 \\
\hline & & PersIntegNorm1 & 0.809 & - & - & - \\
\hline & & PersIntegNorm2 & 0.801 & - & - & - \\
\hline & & PersIntegNorm3 & 0.796 & - & - & - \\
\hline & & PersIntegNorm 4 & 0.715 & - & - & - \\
\hline & & PersIntegNorm7 & 0.736 & - & - & - \\
\hline \multirow{10}{*}{$\begin{array}{c}\text { ESCCB purchase and } \\
\text { use of personal cars }\end{array}$} & \multirow{6}{*}{ Eco-social Use } & & & 0.609 & 0.839 & 0.886 \\
\hline & & ESCCBCInt1 & 0.795 & - & - & - \\
\hline & & ESCCBCInt2 & 0.793 & - & - & - \\
\hline & & ESCCBCInt3 & 0.831 & - & - & - \\
\hline & & ESCCBUInt1 & 0.749 & - & - & - \\
\hline & & ESCCBUInt2 & 0.729 & - & - & - \\
\hline & \multirow{4}{*}{ Eco-social Purchase } & & & 0.754 & 0.837 & 0.902 \\
\hline & & ESCCBPInt1 & 0.883 & - & - & - \\
\hline & & ESCCBPInt2 & 0.842 & - & - & - \\
\hline & & ESCCBPInt3 & 0.878 & - & - & - \\
\hline \multicolumn{4}{|c|}{ Kaiser-Meyer-Olkin (KMO) Measure of Sampling Adequacy } & \multicolumn{3}{|c|}{0.910} \\
\hline \multicolumn{4}{|c|}{ Bartlett's Test } & \multicolumn{3}{|c|}{0.000} \\
\hline \multicolumn{4}{|c|}{ Total Variance Explained } & \multicolumn{3}{|c|}{$52.99 \%$} \\
\hline
\end{tabular}

Notes: ESCCB = eco-socially conscious consumer behavior; $\mathrm{AVE}=$ average variance explained; $\mathrm{CR}=$ composite reliability; $\alpha=$ Cronbach's alpha.

Table 3. Intercorrelations, VIF, and discriminant validity of the constructs.

\begin{tabular}{|c|c|c|c|c|c|c|c|c|}
\hline Constructs & VIF & $\mathbf{A}$ & B & $\mathrm{C}$ & $\mathbf{D}$ & E & $\mathbf{F}$ & G \\
\hline A. Injunctive Norms-Belief Strength & $1.599,1.519$ & 0.836 & - & - & - & - & - & - \\
\hline B. Injunctive Norms-Motivation to Comply & $1.514,1.456$ & $\begin{array}{c}(0.687) \\
0.530 \text { ** }\end{array}$ & 0.813 & - & - & - & - & - \\
\hline C. Descriptive Norms & $1.368,1.291$ & $\begin{array}{c}(0.554) \\
0.435^{* *}\end{array}$ & $\begin{array}{l}(0.514) \\
0.392^{* *}\end{array}$ & 0.832 & - & - & - & - \\
\hline D. Introjected Norms & 1.535 & $\begin{array}{c}(0.355) \\
0.290^{* *}\end{array}$ & $\begin{array}{c}(0.364) \\
0.289^{* *}\end{array}$ & $\begin{array}{c}(0.328) \\
0.266^{* *}\end{array}$ & 0.786 & - & - & - \\
\hline E. Integrated Norms & 1.880 & $\begin{array}{c}(0.547) \\
0.445^{* *}\end{array}$ & $\begin{array}{c}(0.518) \\
0.415^{* *}\end{array}$ & $\begin{array}{l}(0.510) \\
0.415^{* *}\end{array}$ & $\begin{array}{c}(0.706) \\
0.588^{* *}\end{array}$ & 0.772 & - & - \\
\hline F. Eco-social Use & NA & $\begin{array}{c}(0.670) \\
0.546^{* *}\end{array}$ & $\begin{array}{c}(0.669) \\
0.535^{* *}\end{array}$ & $\begin{array}{c}(0.663) \\
0.543^{* *}\end{array}$ & $\begin{array}{c}(0.440) \\
0.378^{* *}\end{array}$ & $\begin{array}{c}(0.705) \\
0.593 \text { ** }\end{array}$ & 0.780 & - \\
\hline G. Eco-social Purchase & NA & $\begin{array}{c}(0.242) \\
0.195^{* *}\end{array}$ & $\begin{array}{c}(0.289) \\
0.231^{* *}\end{array}$ & $\begin{array}{c}(0.367) \\
0.305^{* *}\end{array}$ & $\begin{array}{c}(0.341) \\
0.274^{* *}\end{array}$ & $\begin{array}{c}(0.358) \\
0.299^{* *}\end{array}$ & $\begin{array}{l}(0.373) \\
0316^{* *}\end{array}$ & 0.868 \\
\hline
\end{tabular}

Notes: **: correlations significant at $p<0.01$; VIF, variance inflation factor; values in parentheses are HTMT ratio; values on the diagonal, in bold and italic, are the square root of AVEs, and other values are correlations between the construct. 
Building on the best practices in psychometric data analysis and considering the violation of multivariate normality as a likely assumption, this study performed EFA before hypothesis testing [59]. EFA was conducted using the non-orthogonal rotation method (principal axis factoring with Promax rotation). The Kaiser-Meyer-Olkin (KMO) measure $(\mathrm{KMO}=0.910)$ and Bartlett's test statistic confirmed the appropriateness of the data for EFA analysis [60]. Scrutiny of items was carried out based on factor loadings, and the items with sufficient factor loadings $(\lambda \geq 0.30)$ were retained in the subsequent analysis [60].

Subsequent to the EFA, a first-order complex model was specified. Hypothesis testing was conducted using the same set of data as EFA. While some researchers consider using different datasets for EFA and hypothesis testing, there is a body of literature, which argues that using similar dataset for both EFA and hypothesis testing does not compromise the external validity of the estimates [61,62].

The model presented in Figure 1 suggests that each facet of subjective social norms and personal norms is associated with each dimension of ESCCB related to choice and use of personal cars, and indirect relationships of injunctive and descriptive norms also exist with eco-social use and eco-social purchase through introjected and integrated norms.

The parameters reported in Tables 2 and 3 show the measurement properties of the model of this study. The coefficients of VIF confirm that there are no instances of multicollinearity among exogenous variables (VIF < 4) [63]. For convergent and discriminant validities assessment, average variance extracted (AVE), that is a measure of variance captured by construct, and heterotrait-monotrait (HTMT) ratio of correlation were calculated. The estimates of AVEs $(0.609-0.754>0.5)$ and $\mathrm{HTMT}_{0.90}$ ratio $(0.242-0.706<0.9)$ endorse that convergent and discriminant validity of measurement model is established [64].

\subsection{Statistical Analysis}

Various analytical procedures were applied to test the hypotheses of this study. At first, after descriptives and frequencies, factor analysis was conducted, followed by a structural model evaluation using structural equation modeling (SEM). To estimate the model of this study, a variance-based, partial least squares structural equation modeling (PLS-SEM) approach was utilized. PLS-SEM has been increasingly popular in studies published in the domain of hospitality [65], information science [66], marketing [67], and many others [68,69]. PLS-SEM is considered to be an appealing technique as it enables estimation of complex models (including several constructs and indicators) accommodating for distributional violations, provides a high degree of statistical power, and when the primary goal of the research is theory-testing [70].

\subsection{Structural Model Evaluation}

The results of the path analyses are reported in Table 4 (direct effects) and Table 5 (indirect effects). The estimates of direct effect show that normative beliefs (first element of injunctive norms) are positively associated with integrated $(\beta=0.239, p<0.05)$ and introjected norms $(\beta=0.146, p<0.05)$ as well as with eco-social use $(\beta=0.187, p<0.05)$. However, the relationship between normative beliefs and eco-social purchase is not significant $(p>0.05)$. Similarly, motivations to comply (second element of injunctive norms) are positively associated with integrated norms $(\beta=0.198, p<0.05)$, introjected norms $(\beta=0.158, p<0.05)$, and eco-social use $(\beta=0.205, p<0.05)$, and had no significant relationship with eco-social purchase $(p>0.05)$. Slightly different from the results of the elements of injunctive norms stated above, descriptive norms were associated positively with all the other constructs including integrated norms $(\beta=0.236, p<0.05)$, introjected norms $(\beta=0.142, p<0.05)$, eco-social use $(\beta=0.246, p<0.05)$, and eco-social purchase $(\beta=0.201$, $p<0.05)$. Similarly, introjected norms were significantly associated with eco-social purchase $(\beta=0.140, p<0.05)$ but not with eco-social use $(p>0.05)$, while integrated norms were positively associated with both eco-social use $(\beta=0.314, p<0.05)$ and eco-social purchase $(\beta=0.113, p<0.05)$. 
Table 4. Direct effects of structural model.

\begin{tabular}{lccccc}
\hline \multicolumn{1}{c}{ Predictor } & Dependent Variable & Direct Effect * & S.D & $p$-Value & $f^{2}$ \\
& Integrated Norms & $0.239(0.151,0.332)$ & 0.044 & 0.000 & 0.053 \\
& Introjected Norms & $0.146(0.056,0.247)$ & 0.050 & 0.004 & 0.016 \\
Injunctive Norms_-Belief Strength & Eco-social Use & $0.187(0.112,0.260)$ & 0.038 & 0.000 & 0.047 \\
& Eco-social Purchase & $-0.025(-0.118,0.066)$ & 0.046 & 0.604 & 0.000 \\
\hline & Integrated Norms & $0.198(0.101,0.274)$ & 0.044 & 0.000 & 0.037 \\
& Introjected Norms & $0.158(0.062,0.252)$ & 0.048 & 0.001 & 0.019 \\
Injunctive Norms_-Motivations to Comply & Eco-social Use & $0.205(0.121,0.285)$ & 0.041 & 0.000 & 0.060 \\
& Eco-social Purchase & $0.078(-0.007,0.177)$ & 0.047 & 0.101 & 0.005 \\
\hline & Integrated Norms & $0.236(0.145,0.321)$ & 0.047 & 0.000 & 0.060 \\
& Introjected Norms & $0.142(0.044,0.228)$ & 0.047 & 0.000 & 0.018 \\
Descriptive Norms & Eco-social Use & $0.246(0.168,0.324)$ & 0.041 & 0.000 & 0.097 \\
& Eco-social Purchase & $0.201(0.098,0.296)$ & 0.050 & 0.000 & 0.035 \\
\hline \multirow{2}{*}{ Introjected Norms } & Eco-social Use & $0.015(-0.048,0.078)$ & 0.033 & 0.657 & 0.000 \\
& Eco-social Purchase & $0.140(0.041,0.243)$ & 0.050 & 0.007 & 0.015 \\
\hline \multirow{2}{*}{ Integrated Norms } & Eco-social Use & $0.314(0.223,0.401)$ & 0.045 & 0.000 & 0.113 \\
& Eco-social Purchase & $0.113(0.016,0.209)$ & 0.050 & 0.025 & 0.008 \\
\hline
\end{tabular}

Notes: *: Unstandardized coefficients reported; S.D = standard deviation; values in parenthesis and italics in direct effect column are lower and upper bound bias-corrected confidence intervals of the estimates obtained as a result of bootstrapping procedure; $R^{2}$ (Ecosocial Purchase $=0.146$, Eco-social Use $=0.537$, Personal Integrated Norms $=0.286$, Personal Introjected Norms $=0.125) ; R^{2}$ values of endogenous latent construct: substantial (0.67 or greater), moderate (0.33 to 0.66) or weak (0.19-0.32); Effect Size impact indicator according to Cohen [71] and Chin [72], $f^{2}$ values: 0.35 (large), 0.15 (medium), and 0.02 (small); $Q^{2}=(1-\mathrm{SSE} / \mathrm{SSO}) ; Q^{2}$ eco-social purchase $=0.103$, $Q^{2}$ eco-social use $=0.316, Q^{2}$ personal integrated norms $=0.164, Q^{2}$ personal introjected norms $=0.071 ; Q^{2}$ values greater than zero show predictive relevance of the model [73].

Table 5. Indirect effects of the structural model.

\begin{tabular}{|c|c|c|c|c|c|}
\hline \multirow{2}{*}{ Predictor (X) } & \multicolumn{2}{|c|}{ Consequent } & \multirow{2}{*}{ Indirect Effect ${ }^{a}$} & \multirow{2}{*}{ SD } & \multirow{2}{*}{$t$-Statistic } \\
\hline & Mediator (M) & Dependent Variable (Y) & & & \\
\hline \multirow{4}{*}{$\begin{array}{c}\text { Injunctive Norms-Belief } \\
\text { Strength }\end{array}$} & Integrated norms & \multirow{2}{*}{ Eco-social Use } & $0.074^{* *}(0.042,0.107)$ & 0.017 & 4.487 \\
\hline & Introjected norms & & $0.003^{\text {ns }}(-0.007,0.013)$ & 0.005 & 0.416 \\
\hline & Integrated norms & \multirow{2}{*}{ Eco-social Purchase } & $0.026 *(0.005,0.054)$ & 0.013 & 2.105 \\
\hline & Introjected norms & & $0.020^{\mathrm{ns}}(0.005,0.046)$ & 0.010 & 1.947 \\
\hline \multirow{4}{*}{$\begin{array}{c}\text { Injunctive } \\
\text { Norms-Motivation to } \\
\text { Comply }\end{array}$} & Integrated norms & \multirow{2}{*}{ Eco-social Use } & $0.061^{* *}(0.032,0.098)$ & 0.017 & 3.519 \\
\hline & Introjected norms & & $0.002^{\mathrm{ns}}(-0.007,0.016)$ & 0.005 & 0.411 \\
\hline & Integrated norms & \multirow{2}{*}{ Eco-social Purchase } & $0.024^{\text {ns }}(0.004,0.049)$ & 0.012 & 1.882 \\
\hline & Introjected norms & & $0.022 *(0.006,0.045)$ & 0.010 & 2.156 \\
\hline \multirow{4}{*}{$\begin{array}{l}\text { Subjective Descriptive } \\
\text { Norms }\end{array}$} & Integrated norms & \multirow{2}{*}{ Eco-social Use } & $0.073 * *(0.039,0.119)$ & 0.020 & 3.632 \\
\hline & Introjected norms & & $0.001^{\mathrm{ns}}(-0.007,0.013)$ & 0.005 & 0.418 \\
\hline & Integrated norms & \multirow{2}{*}{ Eco-social Purchase } & $0.026^{\text {ns }}(0.005,0.062)$ & 0.014 & 1.865 \\
\hline & Introjected norms & & 0.019 ns $(0.005,0.046)$ & 0.010 & 1.948 \\
\hline
\end{tabular}

Notes: ${ }^{\text {a }}$ Unstandardized coefficients reported; $: p<0.05,{ }^{* *}: p<0.01{ }^{\text {ns }}=$ not significant; values in parentheses and italics in indirect effects column are lower and upper bound bias-corrected confidence intervals of the estimates obtained as a result of bootstrapping procedure; $\mathrm{SD}=$ standard deviation.

The estimates of indirect effects show that integrated norms positively mediate the relationship of normative belief strength with eco-social use $(\beta=0.074, p<0.05)$ and ecosocial purchase $(\beta=0.026, p<0.05)$. However, introjected norms did not have a significant indirect effect on normative belief strength relationships with eco-social use and eco-social purchase $(p>0.05)$. On the other hand, the relationship between motivations to comply with eco-social use is positively mediated by integrated norms $(\beta=0.061, p<0.05)$, while the mediating effect of introjected norms in the relationship of motivations to comply with eco-social use is not statistically significant $(p>0.05)$. Contrarily, introjected norms positively mediate the relationship of motivations to comply with eco-social purchase 
( $\beta=0.022, p<0.05)$. In contrast, integrated norms fail to generate a statistically significant indirect effect between motivations' relationship to comply with eco-social purchase $(p>0.05)$.

Finally, results concerning the relationships of descriptive norms with eco-social use and eco-social purchase show that only integrated norms mediate the relationship of descriptive norms with eco-social use $(\beta=0.073, p<0.05)$. All other proposed indirect relationships for subjective descriptive norms fail to hold (see Table 5).

\subsection{Robustness Checks}

To establish the robustness of this study's results, an additional set of analyses was conducted primarily focused on identifying any potential existence of nonlinearity and endogeneity. This was per standard practices suggested in the literature concerning PLSSEM reporting [74]. First, we conducted a regression equation specification error test (RESET) to confirm linear relationships between the variables of normative conduct theory and the criterion variables of this study $[75,76]$. The results reported the absence of any nonlinearities; hence, they were considered robust in linear effects.

Endogeneity is a challenge of cause-effect interpretation, mainly due to potentially omitted causes in a model, leading to biased estimates [77]. Since PLS-SEM models are based on methods driven by regression equations, it is suggested to verify the validity of estimates by examining the potential existence of endogeneity [75]. Following the guidelines provided by Hult and Hair [78] and Park and Gupta [79], the Gaussian copula approach was adopted to model the correlation between the scores of lower-order endogenous constructs and error terms. The results showed that neither of the copulas was significant; hence, endogeneity was not present.

\section{Discussion and Conclusions}

Research in the area of norms-driven pro-environmental behaviors is not new. However, the studies thus far have primarily focused on developed industrialized nations. Logically, industrialized nations pose a substantial threat to the environment because of the heightened economic activity causing more GhG emissions. Nevertheless, during the last couple of decades, the changes in countries' economic conditions, earlier considered as underdeveloped, have caused an increase in emissions. These changes in circumstances indicate the need to study the phenomenon of eco-social behaviors in these countries. The current study reported here is an attempt to respond to this changing situation.

Precisely, the findings of this study imply that individuals are susceptible to social expectations to purchase AFVs and use personal cars to consider environmental issues (reduce personal car use) (for complete results of hypotheses, please see Appendix A, Table A1). Furthermore, individuals' self-realization related to moral practices concerning the choice and use of cars facilitates the social pressure toward such behaviors; hence, there is more inclination toward buying AFVs and eco-social use of personal cars. These findings are in line with the theorizing in the literature that social pressure or expectations modify an individual's feeling of responsibility or guilt and strengthen the perceptions of moral obligation toward the environment and nature [20,31].

The findings of this study particularly provide a more detailed explanation of each of the manifest dimensions of subjective social norms and personal norms and their relation to eco-social use and eco-social purchase (underlying dimensions of ESCCB related to choice and use of personal cars). The direct effects model results show that normative beliefs and motivations to comply (components of injunctive norms) are influential in describing eco-social use but not eco-social purchase. This assertion is plausible because purchasing AFV is a high-involvement decision, and mere social expectations might not justify the economic trade-off with environmental goals [80]. On the other hand, the results show that descriptive norms associate positively with both eco-social and eco-social purchases. This evidence suggests that actual proof of others doing a particular action is instrumental in shaping one's perceptions about such behaviors or considering such 
actions to be "normal", thus influencing them to engage in performing such behaviors [81]. Similarly, both introjected and integrated norms are positively associated with eco-social choice and the use of personal cars. This is an expected outcome as individuals who ascribe the ethical use of cars and buy an AFV as their moral obligation are much more likely to behave in that manner [31].

Theoretically, this study expands the extant literature related to norms-driven sustainable consumption. The estimates of indirect effects present mixed findings; that is, some of this study's proposed relationships hold while others fail to receive statistical support. The results reveal that integrated norms link both injunctive and descriptive subjective norms with eco-social use. This evidence indicates that individuals' perceptions of others' expectations about, and actual involvement in, specific behaviors lead to the increased realization of moral obligation toward the eco-social use of personal cars, and this ends up developing positive eco-social use intentions. Interestingly, integrated norms' indirect effect is almost at the same magnitude for injunctive and descriptive norms. Therefore, it can be inferred that the intentions of personal cars' eco-social use are equally influenced by individuals' felt moral obligation in response to social pressure and perceptions of others using personal cars eco-socially. Contrarily, however, integrated norms could only link the normative beliefs strength with the eco-social purchase, and other proposed linkages could not receive adequate statistical support. As explained in earlier sections, an eco-social purchase is a high-involvement decision; therefore, others' social expectations and actual behaviors may not exert much force to change individuals' perceptions of moral obligation toward buying AFVs. Overall, modifying individuals' perceptions of moral obligation toward the eco-social use of cars is relatively more straightforward than eco-social purchase through exerting social pressure and highlighting that others are also involved in the eco-social use of personal cars. The possibility of promoting eco-social purchases in this conceptual schema may not be entirely ruled out. However, the evidence suggests that the strength of normative belief alone can do little to mold individuals' integrated norms.

As for the mediating role of introjected norms, the only motivation to comply is associated with eco-social purchase through introjected norms. This shows that individuals who try to comply with the referent and feel guilt (or pride) perceive that others (referent) expect them to choose an AFV while deciding to buy a personal car. The individual's perceptions of guilt or pride are not influential in any other proposed relation. Logically, emotions of guilt or pride are relatively momentary and fragile states that perish quickly and may not translate into the formation of eco-social behaviors or behavioral intentions for purchases of high-involvement products [20,31,33,82].

The results of this study provide at least two important implications for AFV marketers. First, as the findings evince that injunctive and descriptive norms are essential correlates of eco-social use and purchase, it seems imperative to use persuasive messages surrounding these variables to mainstream (or normalize) eco-social use and purchase behaviors. People rely on others' suggestions or expectations and observe the ongoing trends before deciding on buying unconventional products requiring the processing of new information and having more risk. Marketers should provide cues to consumers to assist them in making such decisions, with messages featuring that other people are also using personal cars ethically and prefer to buy AFVs. Notably, in societies like Pakistan (a collectivist culture) where decision making concerning the purchase of cars is highly dependent on others' opinions (as also argued in the theory of Diffusion of Innovations) and very often requires the approval of important others, the use of subjective social norms to guide ESCCB related to choice and use of personal cars can be helpful.

Second, the evidence clearly illustrates that personal norms are influenced by social norms and lead to eco-social purchase and use of cars. It is pertinent to acknowledge that subjective social norms or personal norms alone are not the sole determinants of ESCCB related to purchasing and using personal cars. Therefore, an objective link is required between the two to promote ESCCB related to personal cars' purchase and use. This knowledge has important implications for marketers trying to understand how personal 
norms can influence behaviors related to AFVs' use and purchase. Consequently, marketers should seek to challenge and amend individuals' norms by providing verbal or visual illustrations of how authority figures adhere to pro-environmental norms and expect the same from individuals (followers). This study is based on data collected from metropolitan cities and ignores the representation of smaller towns. Big cities have a population with a better realization of environmental issues and higher education levels, and the direct influence of environmental problems they experience in their lives makes them more sensitive to environmental improvement messages. Future studies could collect data from a more diverse population to substantiate whether normative influences hold in other population segments. The data collected in this study were based on self-reported behaviors. A common issue with such an approach is the extraneous impact of social desirability, which is not accounted for in this study. Future researchers may consider accommodating social desirability bias to obtain more reliable estimates. An actionable approach can be using actual behavior over time-lag design.

Author Contributions: Writing — original draft preparation, M.A.S.; data curation, H.I.; methodology, R.A.A. All authors have read and agreed to the published version of the manuscript.

Funding: The research was supported by Charles Darwin University through its 'Open Access Support for Increased Citations (OASIC) initiative.

Institutional Review Board Statement: The study was conducted according to the guidelines of National Health and Medical Research Committee (NHMRC) protocols and approved by the Human Research Ethics Committee (HREC) of James Cook University Australia under approval number H6869.

Informed Consent Statement: Informed consent was obtained from all subjects involved in the study.

Data Availability Statement: Data are not publicly available for this article.

Conflicts of Interest: The authors declare no conflict of interest.

Appendix A

Table A1. Summary of results of hypotheses.

\begin{tabular}{|c|c|c|}
\hline Hypotheses & Statement & Result \\
\hline H1a & Descriptive norms are positively associated with eco-social purchase of personal cars & Supported \\
\hline $\mathrm{H} 1 \mathrm{~b}$ & Descriptive norms are positively associated with eco-social use of personal cars & Supported \\
\hline $\mathrm{H} 2 \mathrm{a}$ & Injunctive norms are positively associated with eco-social purchase of personal cars & Not supported \\
\hline $\mathrm{H} 2 \mathrm{~b}$ & Injunctive norms are positively associated with eco-social use of personal cars & Supported \\
\hline $\mathrm{H} 3 \mathrm{a}$ & Integrated norms are positively associated with eco-social purchase of personal cars & Supported \\
\hline $\mathrm{H} 3 \mathrm{~b}$ & Integrated norms are positively associated with eco-social use of personal cars & Supported \\
\hline $\mathrm{H} 4 \mathrm{a}$ & Introjected norms are positively associated with eco-social purchase of personal cars & Supported \\
\hline $\mathrm{H} 4 \mathrm{~b}$ & Introjected norms are positively associated with eco-social use of personal cars & Not supported \\
\hline H5a & Injunctive norms are associated with integrated norms & Supported \\
\hline $\mathrm{H} 5 \mathrm{~b}$ & Injunctive norms are associated with introjected norms & Supported \\
\hline H6a & Descriptive norms are associated with integrated norms & Supported \\
\hline $\mathrm{H} 6 \mathrm{~b}$ & Descriptive norms are associated with introjected norms & Supported \\
\hline $\mathrm{H7a}$ & Integrated norms mediate the relationship of injunctive norms with eco-social purchase of personal cars & Supported \\
\hline $\mathrm{H7b}$ & Integrated norms mediate the relationship of injunctive norms with eco-social use of personal cars & Supported \\
\hline H8a & Introjected norms mediate the relationship of injunctive norms with eco-social purchase of personal cars & Supported \\
\hline $\mathrm{H} 8 \mathrm{~b}$ & Introjected norms mediate the relationship of injunctive norms with eco-social use of personal cars & Not supported \\
\hline H9a & Integrated norms mediate the relationship of descriptive norms with eco-social purchase of personal cars & Not Supported \\
\hline $\mathrm{H} 9 \mathrm{~b}$ & Integrated norms mediate the relationship of descriptive norms with eco-social use of personal cars & Supported \\
\hline $\mathrm{H} 10 \mathrm{a}$ & Introjected norms mediate the relationship of descriptive norms with eco-social purchase of personal cars & Not supported \\
\hline $\mathrm{H} 10 \mathrm{~b}$ & Introjected norms mediate the relationship of descriptive norms with eco-social use of personal cars & Not supported \\
\hline
\end{tabular}




\section{Appendix B}

Table A2. Description of measurement instrument.

\begin{tabular}{|c|c|c|}
\hline Constructs & Items & Description of Items \\
\hline \multirow{5}{*}{ 1. Injunctive Norms } & SbInNr1 & $\begin{array}{l}\text { People who are important to me will support me when I drive an } \\
\text { environment-friendly car }\end{array}$ \\
\hline & SbInNr2 & $\begin{array}{l}\text { People who are important to me try to convince me to drive an } \\
\text { environment-friendly car }\end{array}$ \\
\hline & SbInNr3 & $\begin{array}{l}\text { Most people who are important to me think I should buy an } \\
\text { environment-friendly car }\end{array}$ \\
\hline & SbInNr5 & $\begin{array}{l}\text { People whose opinions I value would prefer me to do carpooling whenever } \\
\text { possible for commuting }\end{array}$ \\
\hline & SbInNr6 & $\begin{array}{l}\text { Many of the people that are important to me insinuated that I should consider } \\
\text { environmental protection while buying a car }\end{array}$ \\
\hline \multirow{3}{*}{ 2. Descriptive Norms } & SbDNr1 & Most of the people that are important to me own environment-friendly cars \\
\hline & $\mathrm{SbDNr} 2$ & $\begin{array}{l}\text { I believe that most of the people that are important to me are considering buying } \\
\text { an environmentally friendly car }\end{array}$ \\
\hline & $\mathrm{SbDNr} 3$ & Most of the people that are important to me do carpooling for commuting \\
\hline \multirow{3}{*}{ 3. Eco-social Purchase } & ESCBPInt1 & $\begin{array}{l}\text { I would buy an alternative fuel vehicle even if its quality is lower than a } \\
\text { conventional car }\end{array}$ \\
\hline & ESCBPInt2 & $\begin{array}{l}\text { I would buy an alternative fuel vehicle even if its performance is lower than a } \\
\text { conventional car }\end{array}$ \\
\hline & ESCBPInt3 & I would buy an alternative fuel vehicle even if it has a less appealing design \\
\hline \multirow{3}{*}{ 4. Eco-social Conservation } & ESCBCInt1 & $\begin{array}{l}\text { I have selected a car with a high rear axle ration since that produces the least } \\
\text { friction and saves energy }\end{array}$ \\
\hline & ESCBCInt2 & $\begin{array}{l}\text { I avoid using wide thread tires since that causes road friction and consumes } \\
\text { more fuel }\end{array}$ \\
\hline & ESCBCInt3 & I consider using radial tires since that helps to preserve fuel resources \\
\hline \multirow{3}{*}{ 5. Eco-social Use } & ESCBUInt1 & $\begin{array}{l}\text { If I have multiple car choices available, given all other factors are the same, I will } \\
\text { choose the one with better environmental performance }\end{array}$ \\
\hline & ESCBUInt2 & $\begin{array}{l}\text { Knowing that excessive speed is inefficient, requiring more energy to stop the } \\
\text { car, I consider observing speed limits }\end{array}$ \\
\hline & ESCBUInt3 & $\begin{array}{l}\text { Knowing that excessive speed is inefficient, requiring more energy to stop the } \\
\text { car, I consider observing a steady pace }\end{array}$ \\
\hline \multirow{5}{*}{ 6. Integrated Norms } & PersIntegNorm 1 & $\begin{array}{l}\text { I feel an obligation to choose an environment-friendly car instead of a } \\
\text { traditional one }\end{array}$ \\
\hline & PersIntegNorm2 & I feel personally obliged to reduce the use of a personal car as much as possible \\
\hline & PersIntegNorm3 & $\begin{array}{l}\text { Regardless of what others do, I feel it is my moral obligation to use an } \\
\text { environment-friendly car }\end{array}$ \\
\hline & PersIntegNorm 4 & $\begin{array}{l}\text { Regardless of what others do, I feel it is my moral obligation to avoid using the } \\
\text { car as much as possible for commuting }\end{array}$ \\
\hline & PersIntegNorm7 & $\begin{array}{l}\text { I feel it obligatory to bear the environment and nature in mind in my daily life } \\
\text { behavior }\end{array}$ \\
\hline \multirow{4}{*}{ 7. Introjected Norms } & PersIntroNorm3 & $\begin{array}{l}\text { I sometimes have a bad conscience because I use my personal car excessively } \\
\text { when I can avoid it }\end{array}$ \\
\hline & PersIntroNorm 4 & I sometimes have a bad conscience that I own a powerful and spacious car \\
\hline & PersIntroNorm5 & I would sometimes have a bad conscience if I owned a powerful and spacious car \\
\hline & PersIntroNorm6 & $\begin{array}{l}\text { I sometimes have a bad conscience that I am using my personal car when I can } \\
\text { use public transport }\end{array}$ \\
\hline
\end{tabular}

\section{References}

1. Taufique, K.M.R.; Vocino, A.; Polonsky, M.J. The influence of eco-label knowledge and trust on pro-environmental consumer behaviour in an emerging market. J. Strateg. Mark. 2017, 25, 511-529. [CrossRef]

2. Huang, Y.-C.; Yang, M.; Wang, Y.-C. Effects of green brand on green purchase intention. Mark. Intell. Plan. 2014, 32, $250-268$. [CrossRef] 
3. Del Rio, M.; Hargrove, W.L.; Tomaka, J.; Korc, M. Transportation Matters: A Health Impact Assessment in Rural New Mexico. Int. J. Environ. Res. Public Health 2017, 14, 629. [CrossRef] [PubMed]

4. Adnan, N.; Nordin, S.M.; Amini, M.H.; Langove, N. What make consumer sign up to PHEVs? Predicting Malaysian consumer behavior in adoption of PHEVs. Transp. Res. Part A Policy Pract. 2018, 113, 259-278. [CrossRef]

5. Chen, S.-Y. Using the sustainable modified TAM and TPB to analyze the effects of perceived green value on loyalty to a public bike system. Transp. Res. Part A Policy Pract. 2016, 88, 58-72. [CrossRef]

6. Saleem, M.A.; Eagle, L.; Low, D. Market segmentation based on eco-socially conscious consumers' behavioral intentions: Evidence from an emerging economy. J. Clean. Prod. 2018, 193, 14-27. [CrossRef]

7. Saleem, M.A.; Eagle, L.; Low, D. Climate change behaviors related to purchase and use of personal cars: Development and validation of eco-socially conscious consumer behavior scale. Transp. Res. Part D Transp. Environ. 2018, 59, 68-85. [CrossRef]

8. Mannberg, A.; Jansson, J.; Pettersson, T.; Brännlund, R.; Lindgren, U. Do tax incentives affect households' adoption of 'green' cars? A panel study of the Stockholm congestion tax. Energy Policy 2014, 74, 286-299. [CrossRef]

9. Wadud, Z.; MacKenzie, D.; Leiby, P. Help or hindrance? The travel, energy and carbon impacts of highly automated vehicles. Transp. Res. Part A Policy Pract. 2016, 86, 1-18. [CrossRef]

10. Chowdhury, M.; Salam, K.; Tay, R. Consumer preferences and policy implications for the green car market. Mark. Intell. Plan. 2016, 34, 810-827. [CrossRef]

11. Coad, A.; de Haan, P.; Woersdorfer, J.S. Consumer support for environmental policies: An application to purchases of green cars. Ecol. Econ. 2009, 68, 2078-2086. [CrossRef]

12. Oliver, J.D.; Lee, S.H. Hybrid car purchase intentions: A cross-cultural analysis. J. Consum. Mark. 2010, 27, 96-103. [CrossRef]

13. Hennessy, H.; Tol, R.S.J. The impact of tax reform on new car purchases in Ireland. Energy Policy 2011, 39, 7059-7067. [CrossRef]

14. Nayum, A.; Klöckner, C.A.; Prugsamatz, S. Influences of car type class and carbon dioxide emission levels on purchases of new cars: A retrospective analysis of car purchases in Norway. Transp. Res. Part A Policy Pract. 2013, 48, 96-108. [CrossRef]

15. Bobeth, S.; Kastner, I. Buying an electric car: A rational choice or a norm-directed behavior? Transp. Res. Part F Traffic Psychol. Behav. 2020, 73, 236-258. [CrossRef]

16. Belgiawan, P.F.; Schmöcker, J.-D.; Fujii, S. Effects of Peer Influence, Satisfaction and Regret on Car Purchase Desire. Procedia Environ. Sci. 2013, 17, 485-493. [CrossRef]

17. Saleem, M.A.; Eagle, L.; Low, D. Determinants of eco-socially conscious consumer behavior toward alternative fuel vehicles. J. Consum. Mark. 2021, 38, 211-228. [CrossRef]

18. Cialdini, R.B.; Reno, R.R.; Kallgren, C.A. A focus theory of normative conduct: Recycling the concept of norms to reduce littering in public places. J. Personal. Soc. Psychol. 1990, 58, 1015-1026. [CrossRef]

19. Ellemers, N.; Haslam, S. Social identity theory. In Handbook of Theories of Social Psychology; Van Lange, P.A., Kruglanski, A.W., Higgins, E.T., Eds.; SAGE Publications Ltd.: Thousand Oaks, CA, USA, 2012; Volume 2, pp. 379-398.

20. Morris, M.W.; Hong, Y.-y.; Chiu, C.-y.; Liu, Z. Normology: Integrating insights about social norms to understand cultural dynamics. Organ. Behav. Hum. Decis. Process. 2015, 129, 1-13. [CrossRef]

21. Fishbein, M.; Ajzen, I. Predicting and Changing Behavior: The Reasoned Action Approach; Psychology Press: New York, NY, USA, 2010.

22. Thøgersen, J. Norms for environmentally responsible behaviour: An extended taxonomy. J. Environ. Psychol. 2006, 26, 247-261. [CrossRef]

23. Schwartz, S.H.; Cieciuch, J.; Vecchione, M.; Torres, C.; Dirilen-Gumus, O.; Butenko, T. Value tradeoffs propel and inhibit behavior: Validating the 19 refined values in four countries. Eur. J. Soc. Psychol. 2017, 47, 241-258. [CrossRef]

24. Cialdini, R.B.; Kallgren, C.A.; Reno, R.R. A Focus Theory of Normative Conduct: A Theoretical Refinement and Reevaluation of the Role of Norms in Human Behavior. In Advances in Experimental Social Psychology; Zanna, M.P., Ed.; Academic Press: New York, NY, USA, 1991; Volume 24, pp. 201-234.

25. Arpita, K. Antecedents to green buying behaviour: A study on consumers in an emerging economy. Mark. Intell. Plan. 2015, 33, 309-329. [CrossRef]

26. Kim, H.; Lee, E.-J.; Hur, W.-M. The Normative Social Influence on Eco-Friendly Consumer Behavior: The Moderating Effect of Environmental Marketing Claims. Cloth. Text. Res. J. 2012, 30, 4-18. [CrossRef]

27. Jiang, K.; Ling, F.; Feng, Z.; Wang, K.; Shao, C. Why do drivers continue driving while fatigued? An application of the theory of planned behaviour. Transp. Res. Part A Policy Pract. 2017, 98, 141-149. [CrossRef]

28. Farrow, K.; Grolleau, G.; Ibanez, L. Social Norms and Pro-environmental Behavior: A Review of the Evidence. Ecol. Econ. 2017, 140, 1-13. [CrossRef]

29. Melvin, A.; Elliott, C.G.; Bang, F.; Roberts, K.C.; Thompson, W.; Prince, S.A. Population health measurement of social norms for sedentary behaviour: A systematic review. Psychol. Sport Exerc. 2020, 47, 101631. [CrossRef]

30. Bergquist, M.; Nilsson, A.; Schultz, W.P. A meta-analysis of field-experiments using social norms to promote pro-environmental behaviors. Glob. Environ. Chang. 2019, 59, 101941. [CrossRef]

31. Ünal, A.B.; Steg, L.; Gorsira, M. Values Versus Environmental Knowledge as Triggers of a Process of Activation of Personal Norms for Eco-Driving. Environ. Behav. 2017, 50, 1092-1118. [CrossRef] [PubMed]

32. Jansson, J.; Pettersson, T.; Mannberg, A.; Brännlund, R.; Lindgren, U. Adoption of alternative fuel vehicles: Influence from neighbors, family and coworkers. Transp. Res. Part D Transp. Environ. 2017, 54, 61-73. [CrossRef] 
33. Onwezen, M.C.; Antonides, G.; Bartels, J. The Norm Activation Model: An exploration of the functions of anticipated pride and guilt in pro-environmental behaviour. J. Econ. Psychol. 2013, 39, 141-153. [CrossRef]

34. Hänninen, N.; Karjaluoto, H. Environmental values and customer-perceived value in industrial supplier relationships. J. Clean. Prod. 2017, 156, 604-613. [CrossRef]

35. Yuda Bakti, I.G.M.; Rakhmawati, T.; Sumaedi, S.; Widianti, T.; Yarmen, M.; Astrini, N.J. Public transport users' WOM: An integration model of the theory of planned behavior, customer satisfaction theory, and personal norm theory. Transp. Res. Procedia 2020, 48, 3365-3379. [CrossRef]

36. Klöckner, C.A.; Ohms, S. The importance of personal norms for purchasing organic milk. Br. Food J. 2009, 111, $1173-1187$. [CrossRef]

37. Bamberg, S.; Hunecke, M.; Blöbaum, A. Social context, personal norms and the use of public transportation: Two field studies. J. Environ. Psychol. 2007, 27, 190-203. [CrossRef]

38. Lind, H.B.; Nordfjærn, T.; Jørgensen, S.H.; Rundmo, T. The value-belief-norm theory, personal norms and sustainable travel mode choice in urban areas. J. Environ. Psychol. 2015, 44, 119-125. [CrossRef]

39. Schwartz, S.H. Normative Influences on Altruism. In Advances in Experimental Social Psychology; Leonard, B., Ed.; Academic Press: New York, NY, USA, 1977; Volume 10, pp. 221-279.

40. Deci, E.L.; Ryan, R.M. Intrinsic Motivation. In Corsini Encyclopedia of Psychology; John Wiley \& Sons: Hoboken, NJ, USA, 2010; pp. 1-2. [CrossRef]

41. Bertoldo, R.; Castro, P. The outer influence inside us: Exploring the relation between social and personal norms. Resour. Conserv. Recycl. 2016, 112, 45-53. [CrossRef]

42. Kim, S.H.; Seock, Y.-K. The roles of values and social norm on personal norms and pro-environmentally friendly apparel product purchasing behavior: The mediating role of personal norms. J. Retail. Consum. Serv. 2019, 51, 83-90. [CrossRef]

43. Lede, E.; Meleady, R.; Seger, C.R. Optimizing the influence of social norms interventions: Applying social identity insights to motivate residential water conservation. J. Environ. Psychol. 2019, 62, 105-114. [CrossRef]

44. Savani, K.; Wadhwa, M.; Uchida, Y.; Ding, Y.; Naidu, N.V.R. When norms loom larger than the self: Susceptibility of preferenceChoice consistency to normative influence across cultures. Organ. Behav. Hum. Decis. Process. 2015, 129, 70-79. [CrossRef]

45. Wenzig, J.; Gruchmann, T. Consumer Preferences for Local Food: Testing an Extended Norm Taxonomy. Sustainability 2018, 10, 1313. [CrossRef]

46. Saleemi, U. ‘Big Three' Dominate Pakistan's Car Market for Yet Another Year. Available online: https:/ /www.pakwheels.com/ blog/big-three-dominate-pakistans-car-market-yet-another-year/ (accessed on 14 September 2020).

47. Bickman, L.; Rog, D.J. The SAGE Handbook of Applied Social Research Methods, 2nd ed.; SAGE Publications, Inc.: Thousand Oaks, CA, USA, 2009.

48. Kline, R.B. Principles and Practice of Structural Equation Modeling; Guilford Publications: New York, NY, USA, 2011.

49. Adams, J.; Khan, H.T.A.; Raeside, R.; White, D. Sampling. In Research Methods for Graduate Business and Social Science Students; Sage Publications Inc.: Thousand Oaks, CA, USA, 2007.

50. LaRose, R.; Tsai, H.-y.S. Completion rates and non-response error in online surveys: Comparing sweepstakes and pre-paid cash incentives in studies of online behavior. Comput. Hum. Behav. 2014, 34, 110-119. [CrossRef]

51. Fishbein, M.E.; Ajzen, I. Belief, Attitude, Intention and Behavior: An Introduction to Theory and Research; Addison-Wesley: Boston, MA, USA, 1975.

52. Moons, I.; De Pelsmacker, P. An Extended Decomposed Theory of Planned Behaviour to Predict the Usage Intention of the Electric Car: A Multi-Group Comparison. Sustainability 2015, 7, 6212-6245. [CrossRef]

53. Doran, R.; Larsen, S. The Relative Importance of Social and Personal Norms in Explaining Intentions to Choose Eco-Friendly Travel Options. Int. J. Tour. Res. 2016, 18, 159-166. [CrossRef]

54. ADB. Policy Brief on Female Labor Force Participation in Pakistan. 2016. Available online: https://www.adb.org/sites/default/ files / publication/209661/ female-labor-force-participation-pakistan.pdf (accessed on 22 February 2021).

55. CIA. The World Factbook-Pakistan. 2020. Available online: https://www.cia.gov/library/publications/the-world-factbook/ geos/pk.html (accessed on 12 April 2021).

56. Podsakoff, P.M.; MacKenzie, S.B.; Podsakoff, N.P. Sources of Method Bias in Social Science Research and Recommendations on How to Control It. Annu. Rev. Psychol. 2012, 63, 539-569. [CrossRef] [PubMed]

57. Podsakoff, P.M.; MacKenzie, S.B.; Lee, J.Y.; Podsakoff, N.P. Common method biases in behavioral research: A critical review of the literature and recommended remedies. J. Appl. Psychol. 2003, 88, 879-903. [CrossRef]

58. Kock, N. Common Method Bias in PLS-SEM: A Full Collinearity Assessment Approach. Int. J. e-Collab. 2015, 11, 1-10. [CrossRef]

59. Costello, A.B.; Osborne, J.W. Best Practices in Exploratory Factor Analysis: Four Recommendations for Getting the Most From Your Analysis. Pract. Assess. Res. Eval. 2005, 10,1-9.

60. Yong, A.G.; Pearce, S. A Beginner's Guide to Factor Analysis: Focusing on Exploratory Factor Analysis. Tutor. Quant. Methods Psychol. 2013, 9, 79-94. [CrossRef]

61. Wismeijer, A.A.J. Dimensionality Analysis of the Thought Suppression Inventory: Combining EFA, MSA, and CFA. J. Psychopathol. Behav. Assess. 2012, 34, 116-125. [CrossRef]

62. Saleem, M.A.; Yaseen, A.; Wasaya, A. Drivers of customer loyalty and word of mouth intentions: Moderating role of interactional justice. J. Hosp. Mark. Manag. 2018, 27, 1-28. [CrossRef] 
63. Grewal, R.; Cote, J.A.; Baumgartner, H. Multicollinearity and Measurement Error in Structural Equation Models: Implications for Theory Testing. Mark. Sci. 2004, 23, 519-529. [CrossRef]

64. Hair, J.F., Jr.; Sarstedt, M.; Ringle, C.M.; Gudergan, S.P. Advanced Issues in Partial Least Squares Structural Equation Modeling; SAGE Publications: Thousand Oaks, CA, USA, 2017.

65. Ali, F.; Rasoolimanesh, S.M.; Sarstedt, M.; Ringle, C.M.; Ryu, K. An assessment of the use of partial least squares structural equation modeling (PLS-SEM) in hospitality research. Int. J. Contemp. Hosp. Manag. 2018, 30, 514-538. [CrossRef]

66. Benitez, J.; Henseler, J.; Castillo, A.; Schuberth, F. How to perform and report an impactful analysis using partial least squares: Guidelines for confirmatory and explanatory IS research. Inf. Manag. 2020, 57, 103168. [CrossRef]

67. Ahn, J.; Kwon, J. The role of trait and emotion in cruise customers' impulsive buying behavior: An empirical study. J. Strateg. Mark. 2020, 1-14. [CrossRef]

68. Schirmer, N.; Ringle, C.M.; Gudergan, S.; Feistel, M.S.G. The link between customer satisfaction and loyalty: The moderating role of customer characteristics. J. Strateg. Mark. 2018, 26, 298-317. [CrossRef]

69. Inyang, A.E.; Jaramillo, F. Salesperson implementation of sales strategy and its impact on sales performance. J. Strateg. Mark. 2020, 28, 601-619. [CrossRef]

70. Hair, J.F.; Risher, J.J.; Sarstedt, M.; Ringle, C.M. When to use and how to report the results of PLS-SEM. Eur. Bus. Rev. 2019, 31, 2-24. [CrossRef]

71. Cohen, J. Statistical Power Analysis for the Behavioral Sciences; Taylor \& Francis: New York, NY, USA, 2013.

72. Chin, W.W. How to Write Up and Report PLS Analyses. In Handbook of Partial Least Squares: Concepts, Methods and Applications; Esposito Vinzi, V., Chin, W.W., Henseler, J., Wang, H., Eds.; Springer: Berlin/Heidelberg, Germany, 2010; pp. 655-690.

73. Henseler, J.; Ringle, C.M.; Sinkovics, R.R. The use of partial least squares path modeling in international marketing. In New Challenges to International Marketing; Emerald Group Publishing: Bingley, UK, 2015; pp. 277-319.

74. Sarstedt, M.; Ringle, C.M.; Cheah, J.-H.; Ting, H.; I Moisescu, O.; Radomir, L. Structural model robustness checks in PLS-SEM. Tour. Econ. 2019, 26, 531-554. [CrossRef]

75. Ramsey, J.B. Tests for Specification Errors in Classical Linear Least-Squares Regression Analysis. J. R. Stat. Soc. Ser. B (Methodol.) 1969, 31, 350-371. [CrossRef]

76. Sarstedt, M.; Mooi, E. A Concise Guide to Market Research: The Process, Data, and Methods Using IBM SPSS Statistics; Springer: Berlin/Heidelberg, Germany, 2014.

77. Cooper, B.; Eva, N.; Fazlelahi, F.Z.; Newman, A.; Lee, A.; Obschonka, M. Addressing common method variance and endogeneity in vocational behavior research: A review of the literature and suggestions for future research. J. Vocat. Behav. 2020, 121, 103472. [CrossRef]

78. Hult, G.T.M.; Hair, J.F.; Proksch, D.; Sarstedt, M.; Pinkwart, A.; Ringle, C.M. Addressing Endogeneity in International Marketing Applications of Partial Least Squares Structural Equation Modeling. J. Int. Mark. 2018, 26, 1-21. [CrossRef]

79. Park, S.; Gupta, S. Handling Endogenous Regressors by Joint Estimation Using Copulas. Mark. Sci. 2012, 31, 567-586. [CrossRef]

80. Jansson, J. Consumer eco-innovation adoption: Assessing attitudinal factors and perceived product characteristics. Bus. Strategy Environ. 2011, 20, 192-210. [CrossRef]

81. Rettie, R.; Burchell, K.; Barnham, C. Social normalisation: Using marketing to make green normal. J. Consum. Behav. 2014, 13, 9-17. [CrossRef]

82. Wang, S.-T. Consumer characteristics and social influence factors on green purchasing intentions. Mark. Intell. Plan. 2014, 32, 738-753. [CrossRef] 